This document is the accepted manuscript version of the following article:

Li, L., Hu, R., Huang, J., Bürgi, M., Zhu, Z., Zhong, J., \& Lü, Z. (2020). A farmland biodiversity strategy is needed for China. Nature Ecology \& Evolution. https://doi .org/10.1038/s41559-020-1161-2

\title{
A farmland biodiversity strategy is needed for China
}

2 Authors: $\mathrm{Li} \mathrm{Li}^{1}$, Ruocheng $\mathrm{Hu}^{1,2}$, Jikun Huang ${ }^{3}$, Matthias Bürgi ${ }^{4}$, Ziyun Zhu ${ }^{1}$, Zhi Lü ${ }^{1,2^{*}}$

\section{Affiliations:}

$4 \quad{ }^{1}$ Center for Nature and Society, School of Life Sciences, Peking University, Yiheyuan Road

5 5, Haidian District, Beijing 100871, China.

$6 \quad{ }^{2}$ Shan Shui Conservation Center, Yiheyuan Road 5, Haidian District, Beijing 100871, China.

$7 \quad{ }^{3}$ China Center for Agricultural Policy, School of Advanced Agricultural Sciences, Peking

8 University, 5 Yiheyuan Road, Haidian District, Beijing 100871, China.

$9 \quad{ }^{4}$ Research Unit Land Change Science, Swiss Federal Research Institute WSL, Zürcherstraße

10 111, Birmensdorf 8903, Switzerland.

$11 *$ Correspondence to: luzhi@pku.edu.cn

12 


\section{Abstract:}

14 Countrywide citizen science data show the importance of farmland outside protected areas

15 for China's avifauna. We urge the government of China to develop a national strategy for

16 policy and research to protect biodiversity and traditional knowledge of sustainable

17 agriculture to meet the post-2020 goal of the Convention on Biological Diversity.

19 Main Text:

20 Agricultural lands take up to a third of the earth's terrestrial surface. In recent decades, the 21 expansion and intensification of agricultural land, triggered by the continuous increase in 22 human population and dietary changes, has become one of the direct drivers of Anthropocene

23 biodiversity loss ${ }^{1}$. The expansion of agricultural production, however, has neither always nor

24 everywhere taken place at the expense of biodiversity. Instead, over the course of centuries of

25 development of agricultural practices, a significant number of wild species have adapted or

26 even become dependent on farmland habitats. The exact characteristics of agricultural

27 development are, therefore, relevant to the fate of global biodiversity, and wildlife-friendly

28 farmlands should be considered as valuable ecosystems. Half of the globe’s agricultural lands

29 are distributed in the 17 megadiverse countries, of which China possesses the largest share of

30 the world's agricultural lands at $9.9 \%$ of the global total ${ }^{2,3}$. With its long cultivation history,

31 China has accumulated rich knowledge with regard to sustainable intensive agricultural

32 practices at small scales. The modernization of agriculture in China in recent decades, despite

33 its remarkable success at feeding its large population, has led to the rapid extinction of

34 diverse land-use practices, threatening the coupling of social and ecological systems ${ }^{4}$.

35 Unfortunately, China's National Biodiversity Strategies and Action Plan (NBSAP) for the

36 Convention on Biological Conservation (CBD) fails to recognize traditional agriculture as an 
37 asset for biodiversity conservation bearing its unique cultural heritage ${ }^{5}$, nor the drastic change

38 in agricultural practice as one of the causes of domestic biodiversity loss.

40 Overlooked biodiversity value of farmlands

41 Typically, the value of farmland is considered with regard to food production. China's 42 agricultural policies primarily target this production function of farmland. In China's country 43 enforcement reports for CBD, biodiversity in the agricultural sector related to farmland is 44 exclusively interpreted in terms of genetic resource conservation, invasive species and pest 45 control. The term "biodiversity" was not mentioned in the annual budget of the Ministry of 46 Agriculture and Rural Affairs ${ }^{6}$. China's newly developed land-use planning scheme, "Major

47 Function-Oriented Zones”, aimed at optimizing the state's spatial development pattern in a 48 top-down approach by assigning the territorial space to four types based on development 49 intensity: development-optimized areas, development-prioritized areas, development50 restricted areas, and development-prohibited areas ${ }^{7}$. Each area is assigned to one of the four 51 major functions serving for industrial or urban development, food production, or ecosystem 52 services provisioning ${ }^{7}$. Although biodiversity in development-restricted areas may benefit 53 from strictly regulated land-use intensity, this land-use planning policy has led to the 54 segregation of lands for nature conservation and agricultural production. In other words, 55 under the current land-use policy arrangement in China, only lands designated as Nature 56 Reserve are recognized for sustaining biodiversity ${ }^{8}$.

\section{High biodiversity in China's farmlands}

59 Agriculture takes the most fertile lands in China which also provide abundant resources for 60 associated wild species (Fig. 1a). According to remote sensing data, cultivated landscapes 61 covered 1.79 million $\mathrm{km}^{2}$ in $2015^{9}$, i.e., almost twice as much as China's National Nature 
62 Reserves, stretching over 0.97 million $\mathrm{km}^{2}{ }^{10}$. Data to assess biodiversity distribution in

63 China's farmlands is overall very limited. However, blooming citizen science approaches on

64 bird species resulted in the most comprehensive nationwide avian database with fine-

65 resolution and up-to-date information on species occurrences collectively compiled by over

667,000 bird watchers ${ }^{11}$. Although abundance data remain insufficient in the citizen science

67 database, regional study in Europe has reported congruent trends of avian richness and

68 abundance influenced by different farmland management regimes ${ }^{12}$. Using these bird data as

69 the best available biodiversity indicator, we simulated potential habitats of 1,111 avian

70 species, including 167 national-protected species and 70 threatened species (see

71 Supplementary Methods). Nearly 25\% of the national-protected species and $20 \%$ of the

72 threatened species use farmland as habitat (See Supplementary Methods, Supplementary

73 Table 1). Looking at the top 17\% (the Aichi Target 11) and 50\% (the "Half-Earth"

74 Advocacy $^{12}$ ) simulated avian-species-rich pixels (1-km grain size), the ratio of cultivated

75 landscapes or National Nature Reserves to the $17 \%$ and $50 \%$ pixel areas increases from

$7615.2 \% / 3.6 \%$ to $28.7 \% / 3.9 \%$. The importance of the cultivated landscape is more pronounced

77 for threatened birds, with the ratio reaching $37.6 \% / 3.1 \%$ and $30.5 \% / 3.6 \%$ respectively.

78 Among the 220 birds that use farmland for feeding or nesting, more than half have over 50\%

79 simulated potential habitats in cultivated landscapes (see Supplementary Methods,

80 Supplementary Fig. 1). The potential habitats of the 220 species identify six avian-diverse

81 farming regions of China:1) the Northwest Xinjiang, 2) the Bohai Rim and Parts of the North

82 China Plain, 3) the Sichuan Basin, 4) the Poyang Lake Plain and the Plain of Hunan and

83 Hubei, 5) the Coastal Areas and Plains of the Yellow Sea, and 6) the West Guangdong and

84 East Guangxi Areas (Fig. 1b). Nevertheless, to date there has been a lack of both regulatory

85 and institutional arrangements to support the enormous avian conservation value in these

86 identified species-rich farmland regions. 


\section{CBD post-2020 framework as an opportunity for mainstreaming}

89 China's obligation to conserve biodiversity is bound to its CBD ratification. However, among

90 the eight megadiverse countries that have over $40 \%$ agricultural territory, China is the only

91 nation that lacks explicit farmland biodiversity targets in its $\mathrm{NBSAP}^{5}$. The only other

92 exception is the United States, which is not a CBD signatory. Heading towards the post-2020

93 biodiversity framework, a broad consensus has been reached for setting conservation targets

94 high in order to reverse the steep species-decline trajectory ${ }^{13,14}$. The current global protected

95 area system is unlikely to meet such a requirement ${ }^{15}$. In this context, the post-2020

96 framework may serve as an opportunity for China to review its biodiversity strategies on

97 farmland. On the one hand, China inherits a myriad of sustainable agricultural systems that

98 facilitate the co-existence of humans and nature ${ }^{16}$. The value of this long and rich bio-cultural

99 heritage is a great asset for the future. On the other hand, during the same time period set for

100 achieving the Aichi Targets, China has become the world's largest consumer of chemical

101 fertilizer and pesticide ${ }^{17}$. The rapid agricultural intensification with heavy use of pesticides

102 has profoundly undermined ecosystem services sustained by traditional farming ${ }^{18}$, putting

103 both biodiversity and food safety at risk. Establishing China’s farmland biodiversity strategy

104 requires the recognition of the environmental function of agricultural land at the decision-

105 making level. Farmland has to be valued not only for agricultural production, but also as a

106 shared space within which a great number of species complete their life cycles, especially in

107 areas where farmlands are small and scattered. In this sense, farmland biodiversity is one

108 form of public good produced by agriculture as an environmental externality, which should

109 be integrated into China’s ecological compensation schemes. 
111 To ensure domestic food security, China has set up a redline of 1.2 million $\mathrm{km}^{2}$ of arable land

112 which cannot be transformed into other types of land use. Farmland to be spared for the

113 conservation of birds and other wild fauna and flora is rather limited at present. Thus, new

114 agricultural systems in China should be developed to integrate both traditional wisdom and

115 scientific knowledge of sustainable intensification towards the conservation of focal species

116 in high-priority areas. First, a national baseline of biodiversity distributions in farmlands

117 should be established to set spatial conservation targets, such as within the six avian-diverse

118 farming regions in China. Second, interdisciplinary research projects should be launched to

119 investigate the integration of traditional agricultural knowledge and modern scientific

120 knowledge to foster the successful coupling of sustainable farming with species protection.

121 Third, policy and market incentives should be created to reward wildlife-friendly farming or

122 compensate for farmers' losses in production (i.e., a fund for farmland eco-compensation).

123 Lastly, farmland biodiversity monitoring should be installed to facilitate both action- and

124 performance-based payment. We propose that conserving farmland biodiversity should

125 become part of the jurisdiction of state level administrative responsibility, and research funds

126 should be directed towards finding novel solutions for human-nature coexistence.

\section{References:}

1291 Diaz, S. et al. Summary for policymakers of the global assessment report on

130 biodiversity and ecosystem services of the Intergovernmental Science-Policy

$131 \quad$ Platform on Biodiversity and Ecosystem Services. (2019).

1322 Mittermeier, R. A. Megadiversity: Earth's biologically wealthiest nations.

133 (Agrupacion Sierra Madre, 1997).

$1343 \quad$ FAO. Statistical databases: Land Use Total,

$135 \quad<$ http://www.fao.org/faostat/en/\#data/GL> (2019).

1364 Liu, Y., Duan, M. \& Yu, Z. Agricultural landscapes and biodiversity in China.

137 Agriculture, ecosystems \& environment 166, 46-54 (2013).

1385 Xue, D. et al. China national biodiversity conservation strategy and action plan

139 (2011-2030). (China Environmental Science Press, 2011).

1406 Ministry of Agriculture and Rural Affairs. The annual sectoral budget of the Ministry

141 of Agriculture and Rural Affairs 2019, 
142

143

144

145

146

147

148

149

150

151

152

153

154

155

156

157

158

159

160

161

162

163

164

165

166

167

168

169

170

171

<http://www.moa.gov.cn/gk/cwgk 1/ysjs/201904/P020190402509581207107.pdf> (2019).

7 Fan, J., Tao, A. \& Ren, Q. On the historical background, scientific intentions, goal orientation, and policy framework of major function-oriented zone planning in China. Journal of Resources and Ecology 1, 289-299 (2010).

8 Li, L. \& Lu, Z. Multifunctionality of land and Ecological Compensation: Thoughts on biodiversity mainstreaming. Resource Industrial Economy (2019).

$9 \mathrm{Xu}, \mathrm{X}$. et al. China's Multi-Period Land Use Land Cover Remote Sensing Monitoring Data Set (CNLUCC). Resource and Environment Data Cloud Platform: Beijing, China (2018).

10 Ministry of Ecology and Environment. 2018 Report on the State of the Ecology and Environment in China, <http://www.mee.gov.cn/hjzl/zghjzkgb/lnzghjzkgb/201905/P0201906195876326306 18.pdf> (2019).

$11 \mathrm{Hu}$, R. et al. A bird's view of new conservation hotspots in China. Biological conservation 211, 47-55 (2017).

12 Wilson, E. O. Half-earth: our planet's fight for life. (WW Norton \& Company, 2016).

13 Dinerstein, E. et al. A global deal for nature: Guiding principles, milestones, and targets. Sci Adv 5, eaaw2869 (2019).

14 Mace, G. M. et al. Aiming higher to bend the curve of biodiversity loss. Nature Sustainability 1, 448-451 (2018).

15 Visconti, P. et al. Protected area targets post-2020. Science 364, 239-241 (2019).

16 Koohafkan, P. 21 Globally Important Agricultural Heritage Systems (GIAHS): a Legacy for Food and Nutrition Security. Sustainable Diets: Linking Nutrition and Food Systems, 204 (2018).

17 National Bureau of Statistics of the People's Republic of China. China Statistical Yearbook 2018. (China Statistics Press, 2018).

18 Huang, J. et al. Uncovering the economic value of natural enemies and true costs of chemical insecticides to cotton farmers in China. Environ Res Lett 13, 064027 (2018). 
173 Acknowledgements

174 We are grateful to F. Hua, F. Fassnacht, D. Wilcove, F. Herzog for valuable discussions and

175 comments. G. Gautschi helped us with the English editing of the manuscript.

176

177 Author Contributions

178 Z. L., L. L., J. H. and M. B. conceptualized and framed the main perspective of the comment.

179 R. H. conducted all species modeling and mapping and wrote the chapter of Supplementary

180 Methods. Z. Z. reviewed the current agricultural policies of China. J. H. provided

181 recommendations regarding agricultural policies. L. L. drafted the manuscript, M. B., Z. L.

182 and J. H. revised the content and language of the manuscript.

184 Competing interests

185 The authors declare no competing interests.

187 Fig. 1a The Crested Ibis (Nipponia nippon) depends on rice paddy fields. Benefiting from the 188 conservation measures of maintaining traditional land use and restricting agrochemicals, its 189 numbers have increased from less than a dozen to over 2,000 in the past 30 years. Photo:

190 Dingqian Xiang. Fig. 1b Six avian-diverse farming regions in China. 1) the Northwest

191 Xinjiang, 2) the Bohai Rim and Parts of the North China Plain, 3) the Sichuan Basin, 4) the 192 Poyang Lake Plain and the Plain of Hunan and Hubei, 5) the Coastal Areas and Plains of the 193 Yellow Sea, and 6) the West Guangdong and East Guangxi Areas. 1) and 2) mainly consist of 194 dry farming lands, 4) and 5) are paddy fields, 3) and 6) have both. 

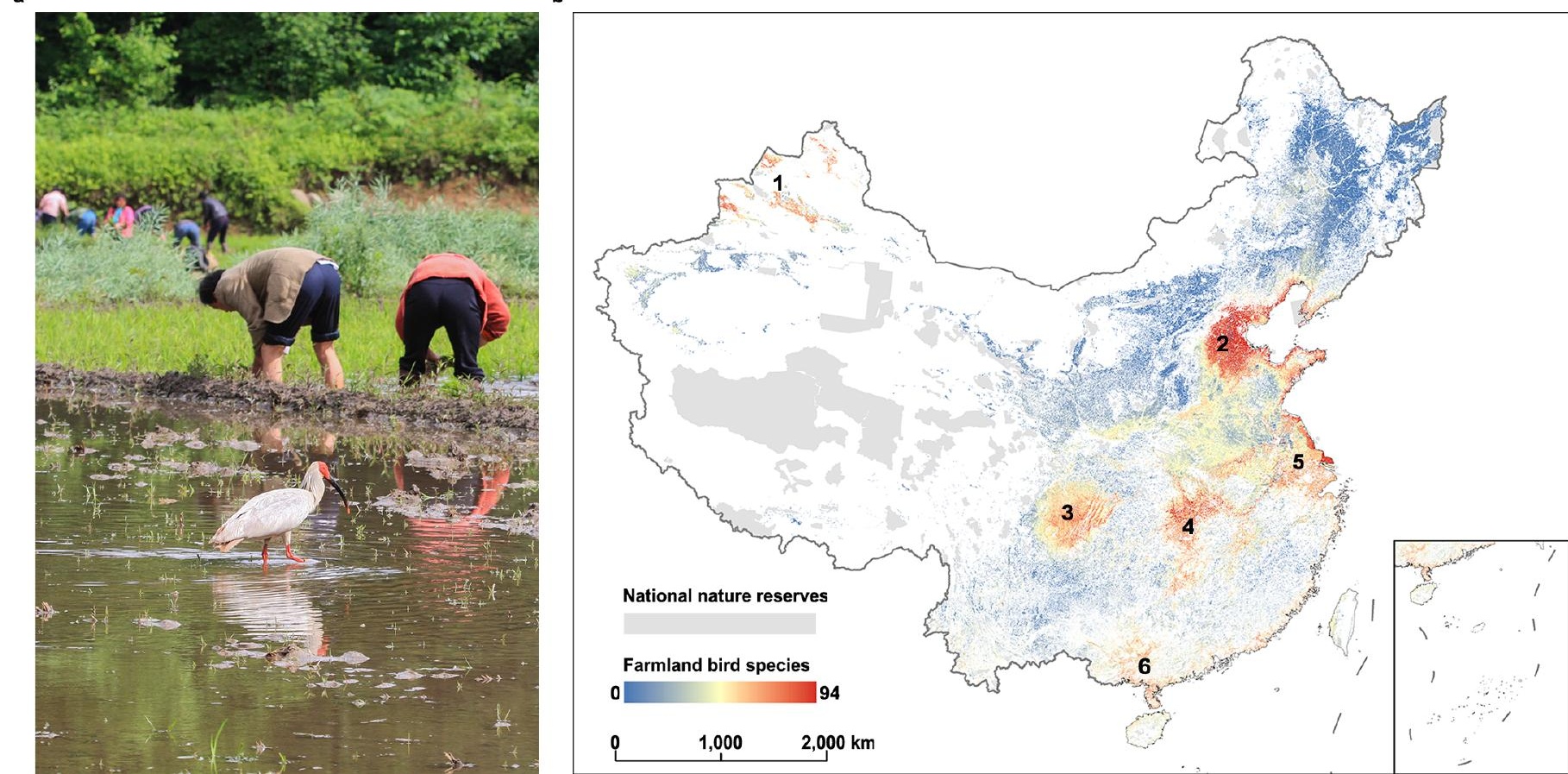